\title{
RESEARCH
}

\section{Short-chain fatty acids as novel therapeutics for gestational diabetes}

\author{
Rebecca Roy', Caitlyn Nguyen-Ngo ${ }^{1}$ and Martha Lappas ${ }^{1,2}$ \\ 'Obstetrics, Nutrition and Endocrinology Group, Department of Obstetrics and Gynaecology, University of Melbourne, Victoria, Australia \\ ${ }^{2}$ Mercy Perinatal Research Centre, Mercy Hospital for Women, Victoria, Australia
}

Correspondence should be addressed to M Lappas: mlappas@unimelb.edu.au

\begin{abstract}
Gestational diabetes mellitus (GDM) affects up to $16 \%$ of pregnant women and is associated with significant long-term health detriments for the mother and her offspring. Two central features of GDM are low-grade inflammation and maternal peripheral insulin resistance, therefore therapeutics which target these may be most effective at preventing the development of GDM. Short-chain fatty acids (SCFAs), such as butyrate and propionate, are metabolites produced from the fermentation of dietary fibre by intestinal microbiota. SCFAs possess anti-inflammatory, anti-obesity and anti-diabetic properties. Therefore, this study aimed to investigate the effect of SCFAs on inflammation and insulin signalling defects in an in vitro model of GDM. Human placenta, visceral adipose tissue (VAT) and s.c. adipose tissue (SAT) were stimulated with either the pro-inflammatory cytokine TNF or bacterial product lipopolysaccharide (LPS). The SCFAs butyrate and propionate blocked TNF- and LPS-induced mRNA expression and secretion of proinflammatory cytokines and chemokines in placenta, VAT and SAT. Primary human cells isolated from skeletal muscle were stimulated with TNF to assess the effect of SCFAs on inflammation-induced defects in the insulin signalling pathway. Butyrate and propionate were found to reverse TNF-induced increases in IRS-1 serine phosphorylation and decreases in glucose uptake. Butyrate and propionate exerted these effects by preventing ERK activation. Taken together, these results suggest that the SCFAs may be able to improve insulin sensitivity and prevent inflammation induced by sterile or bacterial inflammation. Future in vivo studies are warranted to investigate the efficacy and safety of SCFAs in preventing insulin resistance and inflammation associated with GDM.
\end{abstract}

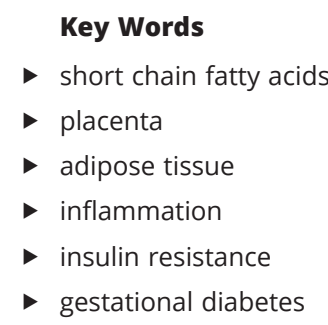

Journal of Molecular

Endocrinology

(2020) 65, 21-34

\section{Introduction}

Gestational diabetes mellitus (GDM) affects up to $16 \%$ of pregnant women globally (Yuen et al. 2019). Additional to the short-term risks of macrosomia and birthing complications, there are long-term risks for both mother and child such as obesity, metabolic syndrome, type 2 diabetes and cardiovascular disease (Reece 2010, Damm et al. 2016). To date, interventions have failed to effectively reduce the burden of disease (Agha-Jaffar et al. 2016). Treatment of GDM with insulin has a short-term focus - it improves pregnancy outcomes, but has little to no impact on the long-term health risks of the next generation ( $\mathrm{Zhu}$ et al. 2019). In addition, there is a daily burden and cost of insulin injections, risk of hypoglycaemia, increased appetite and weight gain (Brawerman \& Dolinsky 2018). 
There is also a concern about the safety of insulin for mother and her baby (Liang et al. 2017). While recent research surrounding lifestyle interventions, such as high plant-based diets and exercise regimes, may mitigate longterm risks, compliance with these regimens is challenging. Accordingly, such interventions do not present a simple, scalable solution that could be applied universally.

GDM is associated with maternal peripheral insulin resistance and low-grade inflammation. Alterations in the insulin signalling pathway, abnormal subcellular localisation of glucose transporters (GLUTs) and reduced insulin-mediated glucose transport have been found in skeletal muscle of women with GDM (Colomiere et al. 2010, Catalano 2014, Friedman 2015). This peripheral insulin resistance results in greater substrate availability for foetal growth and adiposity. Chronic low-grade maternal and placental inflammation are also hallmarks of pregnancies complicated by GDM (Pantham et al. 2015, Nguyen-Ngo et al. 2019). Inflammation is thought to be a driver of the pathophysiology of GDM. Placenta, adipose tissue and skeletal muscle respond to inflammatory insults, such as the cytokine TNF and the bacterial product lipopolysaccharide (LPS), by enhancing the production and expression of pro-inflammatory cytokines and chemokines (Nguyen-Ngo et al. 2019). These proinflammatory mediators induce further inflammation and promote insulin resistance. Thus, there is a need for new approaches that target both inflammation and insulin resistance.

Short-chain fatty acids (SCFAs) have been touted as potential therapeutic agents in many inflammatory and metabolic disorders (Tan et al. 2014, Gill et al. 2018). SCFAs can be produced endogenously through metabolic processes or ingested through dietary fibre that is bacterially fermented in the gut. They are found in high mM concentrations in the gut (Bergman 1990) where they are metabolized by gut enterocytes or transported across the gut epithelium into the bloodstream. Human and experimental animal studies demonstrate a protective role of SCFAs in metabolic disease. In non-pregnant animal models of obesity and diabetes, the addition of SCFAs butyrate and propionate to the diet reduces body weight, adiposity, fasting blood glucose, fasting insulin, and insulin tolerance and improved metabolic activity (Gao et al. 2009, Henagan et al. 2015). In humans, increased gut production of butyrate is associated with improved insulin response after an oral glucose-tolerance test (Sanna et al. 2019). Further, abnormalities in the production of propionate is causally related to an increased risk of type 2 diabetes in humans (Sanna et al. 2019). In pregnant mice fed a high fat diet, butyrate supplementation decreases weight gain, blood glucose and total cholesterol as well as reduces maternal inflammation (Li et al. 2013). There are, however, no studies that have assessed the anti-inflammatory SCFAs in human placenta and adipose tissue. Likewise, no studies have assessed if SCFAs can improve insulin resistance induced by TNF in human skeletal muscle.

Epidemiological evidence suggests that increased dietary fibre consumption is associated with many beneficial health effects including reduced risk of developing cardiovascular disease and diabetes (McNabney \& Henagan 2017). Likewise, total dietary fibre, specifically fruit and cereal fibres, is strongly associated with a reduction of GDM risk by $26 \%$ (Zhang et al. 2006). What is unknown, however, is whether SCFAs contribute to the beneficial effects of a high fibre diet in reducing GDM risk. In keeping with this, no studies have examined the effects of SCFAs on inflammation and insulin resistance associated with GDM using human samples. Thus, the aims of this study were to determine the effect of SCFAs on reducing inflammation in placenta and adipose tissue and skeletal muscle insulin resistance associated with GDM. We hypothesise that SCFAs will reduce inflammation in placenta and adipose tissue induced by TNF and LPS and restore the decrease in glucose uptake in skeletal muscle mediated by TNF.

\section{Materials and methods}

\section{Tissue collection}

Ethics approval for this project was granted by the Mercy Hospital for Women Research and Ethics Committee (Mercy Health, Ethics approval number R04-29). Written, informed consent was obtained from all participating women. Placenta, SAT, VAT and skeletal muscle (from the rectus pyramidalis) were obtained from healthy normal glucose tolerant (NGT) women with a BMI $<30 \mathrm{~kg} / \mathrm{m}^{2}$ who were delivering healthy, singleton infants at term (37-41 weeks of gestation) via elective Caesarean in the absence of labor. The exclusion criteria included: vascular/ renal complication, multiple gestations, GDM, asthma, smokers, preeclampsia, chorioamnionitis, placental abruption, acute foetal distress, and women with any other adverse underlying medical conditions. All tissues were brought to the research laboratory and processed within 15 min of the Caesarean delivery.

\section{Tissue explants}

Tissue explants were used to determine the effect of SCFAs on the mRNA expression and protein release of 
pro-inflammatory cytokines and chemokines in placenta, SAT and VAT. We also tested the mechanism through which SCFAs act, by examining its effect on MAPK signalling pathway protein ERK.

Tissue explants for placenta (Lim et al. 2013b) and adipose tissue (Lappas 2014a) were performed as previously described. Briefly, tissues were washed in PBS and blunt dissected to remove visible connective tissue, vessels and calcium deposits. The processed tissues were then preincubated for $1 \mathrm{~h}$ in Dulbecco's modified Eagle's medium (DMEM) (containing $100 \mathrm{U} / \mathrm{mL}$ penicillin $\mathrm{G}$ and $100 \mu \mathrm{g} / \mathrm{mL}$ streptomycin) at $37^{\circ} \mathrm{C}$ in a humidified incubator of $5 \%$ $\mathrm{CO}_{2}$ and $21 \% \mathrm{O}_{2}$ (adipose tissue) or $8 \% \mathrm{O}_{2}$ (placenta). Tissues were then pre-incubated with $5 \mathrm{mM}$ butyrate or $10 \mathrm{mM}$ propionate (both obtained from Sigma-Aldrich) for $1 \mathrm{~h}$ and then treated with $10 \mu \mathrm{g} / \mathrm{mL}$ LPS (derived from Escherichia coli 026:B6; Sigma-Aldrich) or $10 \mathrm{ng} / \mathrm{mL} \mathrm{TNF}$ (PeproTech) for a further $20 \mathrm{~h}$. The final concentration of butyrate and propionate was based on previous studies in non-gestational tissues (Segain et al. 2000, Voltolini et al. 2012, Hanley et al. 2015) and an initial dose response. A dose response for acetate ( 5 and $20 \mathrm{mM}$ ) demonstrated no effect on TNF-induced IL6 or CXCL8 secretion in placenta or adipose tissue and therefore acetate was not used for any subsequent studies. After a $20 \mathrm{~h}$ incubation with SCFAs, tissues and conditioned media were collected separately and stored at $-80^{\circ} \mathrm{C}$ for analysis by RT-qPCR or ELISA as detailed subsequently. Experiments were performed in duplicate; the average of the duplicate was used for final data analysis. To determine the effect of treatment on cell membrane integrity, the release of the intracellular enzyme lactate dehydrogenase (LDH) into incubation medium was determined as described previously (Lim et al. 2013a). Neither in vitro incubation nor experimental treatment significantly affected $\mathrm{LDH}$ activity in the incubation medium (data not shown). Explants were performed on placenta and VAT obtained from six patients and SAT from seven patients.

To assess the effects of SCFAs on activation of ERK, tissues were incubated with $5 \mathrm{mM}$ butyrate or $10 \mathrm{mM}$ propionate for $20 \mathrm{~h}$ and then treated with $10 \mathrm{ng} / \mathrm{mL}$ TNF or $10 \mu \mathrm{g} / \mathrm{mL}$ LPS for $20 \mathrm{~min}$. Tissues were then collected and stored at $-80^{\circ} \mathrm{C}$ for analysis by Western blotting as detailed subsequently. Experiments were performed from placenta and VAT obtained from five patients.

\section{Glucose uptake in skeletal muscle cells}

Primary skeletal muscle cells were used to determine the effect of SCFAs on insulin-stimulated glucose uptake.
2-NBDG (2-(N-(7-Nitrobenz-2-oxa-1,3-diazol-4-yl) amino)2-deoxyglucose) was used as a fluorescent glucose analogue to monitor glucose uptake. Skeletal muscle cells were isolated from fresh skeletal muscle tissue obtained from pregnant women at the time of term Caesarean section. Skeletal muscle was dissected free of fat and connective tissue before mincing into fine pieces. Finely minced tissue was digested in DMEM containing 0.2\% (wt/vol) collagenase type 1 (Worthington Biochemical, Freehold, NJ, USA) for 60 min in a shaking water bath. The isolate was passed through a $70 \mu \mathrm{m}$ cell strainer and then centrifuged at $500 \mathrm{~g}$ for $10 \mathrm{~min}$. The supernatant was removed and pellet resuspended in $5 \mathrm{~mL}$ of DMEM/F12 (containing $100 \mathrm{U} / \mathrm{mL}$ penicillin $\mathrm{G}$ and $100 \mu \mathrm{G} / \mathrm{mL}$ streptomycin, $10 \%$ heat inactivated FBS). Cells were cultured in flasks coated with $0.2 \%$ gelatin and incubated at $21 \% \mathrm{O}_{2}, 5 \% \mathrm{CO}_{2}$ at $37^{\circ} \mathrm{C}$. At $80 \%$ confluency, cells were plated into black walled 96-well plates in quadruplicate. Confluent cells ( 80\%) were differentiated into myotubes by incubating in DMEM containing $2 \%$ horse serum for 6 days. Cells were then treated with $5 \mathrm{mM}$ butyrate or $10 \mathrm{mM}$ propionate with or without $10 \mathrm{ng} / \mathrm{mL}$ TNF for $20 \mathrm{~h}$. Subsequently, $200 \mu \mathrm{M}$ of 2 -NBDG and $10 \mathrm{nM}$ of insulin were added and incubated for a further $30 \mathrm{~min}$. Media was removed, cells washed three times with PBS and fluorescence intensity quantitated immediately at $540 \mathrm{~nm}$ using FLUOstar Omega (BMG Labtech, Victoria, Australia).

\section{siRNA transfection studies in primary human trophoblast cells}

Human primary trophoblast cells were used to determine if propionate and butyrate elicit their inflammatory effects via activation of the SCFA receptors FFAR2 or FFAR3. Isolation and purification of primary villous trophoblast cells were performed from fresh placenta from non-obese pregnant women. Placental villous cytotrophoblasts were isolated as previously described (Lappas 2014b) by DNase/ trypsin digestion and purified by separation on a Percoll gradient. Briefly, placental villous tissue $(\sim 25 \mathrm{~g})$ was dissected and washed in saline and then digested three times in a HEPES-buffered salt solution containing $0.25 \%$ trypsin and $0.2 \mathrm{mg} / \mathrm{mL}$ DNAse. Tissue was shaken at $37^{\circ} \mathrm{C}$ for $45 \mathrm{~min}$. The cytotrophoblast cells were separated on a Percoll gradient and resuspended in standard cell culture medium (5.5 mM glucose, 44.5\% DMEM, 44.5\% Ham's-F12, and $10 \%$ foetal calf serum supplemented with antibiotics). The cells were plated in 24-well plates at a density of $5 \times 10^{5}$ cells per well. The cells were cultured at 
$37^{\circ} \mathrm{C}$ in $8 \% \mathrm{O}_{2}, 5 \% \mathrm{CO}_{2}$ atmosphere and the cell culture media was changed daily. Transfection of trophoblast cells was performed as previously described (Lappas 2014b) using FFAR2 siRNA (siFFAR2), FFAR3 siRNA (siFFAR3) and negative control siRNA (siCONT) obtained from Ambion (Thermo Fisher Scientific). Cells were transfected with $50 \mathrm{nM}$ siRNA for $48 \mathrm{~h}$, followed by treatment with or without $5 \mathrm{mM}$ butyrate or $10 \mathrm{mM}$ propionate in the presence of $1 \mu \mathrm{g} / \mathrm{mL}$ LPS. After a 20-h incubation, cells and media were collected and stored at $-80^{\circ} \mathrm{C}$ until analysed as detailed subsequently. Experiments were performed on cells isolated from placenta obtained from three patients.

\section{Enzyme immunoassays}

The levels of IL6, GM-CSF and CXCL8 in the incubation media were measured using sandwich ELISA from Invitrogen as per the manufacturer's instructions. The levels of CCL2, CXCL1 and CXCL5 in the incubation media were measured by sandwich ELISA from R\&D Systems as per the manufacturer's instructions. The release of $\mathrm{PGF}_{2 \alpha}$ into the incubation medium was assayed using a commercially available competitive enzyme immunoassay kit as per the manufacturer's specifications (Cayman Chemical Company). The interassay and intraassay coefficients of variation for all assays were less than $10 \%$.

\section{Quantitative RT-PCR (RT-qPCR)}

RNA extractions, cDNA synthesis and RT-qPCR were performed as previously described (Lim et al. 2013a) using $100 \mathrm{nM}$ of pre-designed and validated QuantiTect primers (primer sequences not available) (Qiagen). The primers with catalogue number are as follows: GM-CSF, QT00000896; IL1A, QT00001127; IL1B, QT00021385; IL6, QT00083720; CCL2, QT00212730; CCL3, QT01008063; CCL4, QT01008070; CCL8, QT00212639; CXCL1, QT00199752; CXCL2, QT00013104; CXCL5, QT00203686; CXCL8, QT00000322; CXCL10, QT01003065; SDHA, QT00059486; and YWHAZ, QT00087962. Target gene Ct values were normalised to the average YWHAZ and SDHA Ct values of the same cDNA sample. Fold differences were determined using the comparative $\mathrm{Ct}$ method.

\section{Western blotting}

Western blotting was performed as previously described (Lappas et al. 2004). Mouse monoclonal pERK (sc-7383; Santa Cruz Biotechnology), rabbit polyclonal ERK (sc-93;
Santa Cruz Biotechnology), and rabbit polyclonal IRS-1 (sc-560; Santa Cruz Biotechnology) were used at $0.2 \mu \mathrm{g} / \mathrm{mL}$. Rabbit polyclonal pIRS-1 (Ser307) (07-247; Upstate Biotechnology) was diluted 1:1000. Membranes were viewed and analysed using the ChemiDoc MP system (Bio-Rad Laboratories). Semi-quantitative analysis of the relative density of the bands in Western blots was performed using Quantity One 4.2.1 image analysis software (Bio-Rad Laboratories).

\section{Statistical analysis}

All statistical analyses were undertaken using GraphPad Prism (GraphPad Software). Normality of the data was assessed using the Shapiro-Wilk test. Non-normalised data were logarithmically transformed before analysis by a repeated measures one-way ANOVA (with LSD posthoc testing to discriminate among the means). Statistical significance was ascribed to a $P$ value $\leq 0.05$.

\section{Results}

\section{Effect of butyrate and propionate on pro-inflammatory cytokines}

The effect of butyrate and propionate on LPS- or TNFinduced expression and secretion of pro-inflammatory cytokines in placenta and adipose tissue (VAT and SAT) is demonstrated in Fig. 1 and 2, respectively. The levels of GM-CSF and IL1B in the incubation media of placenta, VAT and SAT, and the levels of IL1A in the incubation media of VAT and SAT were below the sensitivity of the assay and thus not assessed.

In placenta, LPS and TNF treatment significantly increased GM-CSF and IL1B mRNA expression (Fig. 1A and D) and IL1A and IL6 secretion (Fig. 1C and F). On the other hand, only LPS significantly increased IL1A (Fig. 1B) and IL6 (Fig. 1E) mRNA expression. Pre-treatment with either butyrate or propionate significantly suppressed LPS- and TNF-induced mRNA expression and/or protein release of GM-CSF, IL1A, IL1B and IL6.

In VAT, LPS and TNF significantly increased GM-CSF, IL1A and IL6 mRNA expression (Fig. 2A, B and C) and IL6 secretion (Fig. 2D). Butyrate significantly suppressed LPS- and TNF-induced GM-CSF, IL1A and IL6 mRNA expression (Fig. 2A, B and C). In addition, propionate significantly suppressed LPS-induced GM-CSF (Fig. 2A) and IL6 (Fig. 2C) mRNA expression. There was no effect of butyrate or propionate on LPS- or TNF-induced IL6 secretion (Fig. 2D). 

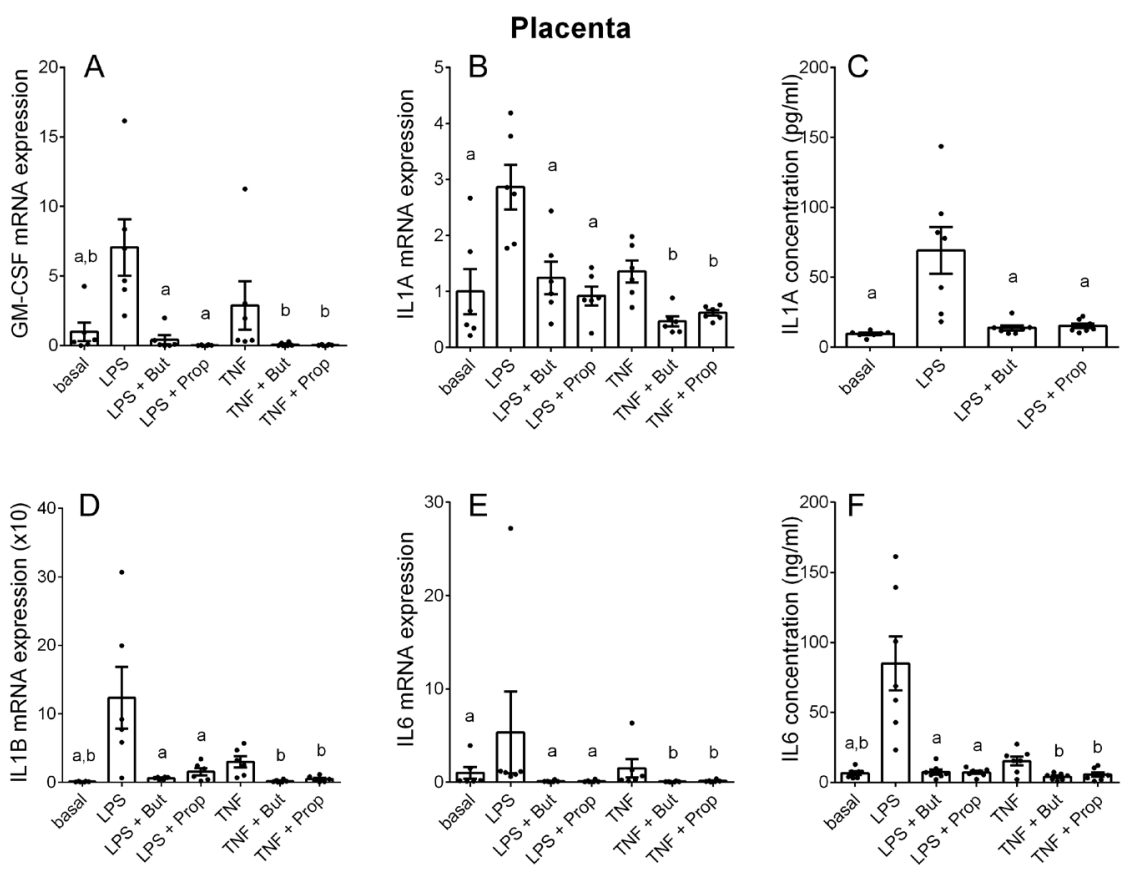

Effect of SCFAs on pro-inflammatory cytokines in placenta. Human placenta was incubated in the absence or presence of $5 \mathrm{mM}$ butyrate (But) or $10 \mathrm{mM}$ propionate (Prop) for $1 \mathrm{~h}$ and then treated with $10 \mu \mathrm{g} / \mathrm{mL}$ LPS or $10 \mathrm{ng} / \mathrm{mL}$ TNF for a further $20 \mathrm{~h}(n=7$ patients). (A, B, D and E) GM-CSF, IL1A, IL1B and IL6 mRNA expression was analysed by RT-qPCR and fold change was calculated relative to basal. ( $C$ and F) The concentration of IL1A and IL6 in the incubation medium was assayed by ELISA. For all graphs, individual data points represent seven independent experiments and displayed as mean \pm S.E.M. ${ }^{a} P \leq 0.05$ vs LPS, ${ }^{\circ} P \leq 0.05$ VS TNF; repeated measures one-way ANOVA.
In SAT, LPS and TNF significantly increased GM-CSF, IL1A and IL6 mRNA expression (Fig. 2E, F and G) and IL6 secretion (Fig. 2H). Butyrate significantly attenuated LPS-induced GM-CSF, IL1A and IL6 mRNA expression and IL6 secretion. Propionate significantly attenuated LPSinduced GM-CSF and IL6 mRNA expression (Fig. 2E and $\mathrm{G})$; however, there was no effect of propionate on LPSinduced IL1A mRNA expression or IL6 secretion (Fig. 2F and $\mathrm{H})$. Additionally, there was no effect of butyrate or propionate on TNF-induced GM-CSF, IL1A and IL6 mRNA expression and IL6 secretion (Fig. 2E, F, G and H).

\section{Effect of butyrate and propionate on chemokines}

The effect of butyrate and propionate on LPS- or TNFinduced expression and secretion of CCL and CXCL chemokines in placenta is demonstrated in Fig. 3 and 4, in VAT in Fig. 5 and 6, and in SAT in Fig. 7 and 8. In all three tissues, the levels of CCL3, CCL8, CXCL2 and CXCL10 in the incubation media were below the sensitivity of the assay and thus not assessed.

In placenta, LPS and TNF significantly increased CCL3, CCL4, and CCL8 mRNA expression (Fig. 3C, D and F) and CCL2 and CCL4 secretion (Fig. 3B and E). Likewise, LPS and TNF treatment significantly upregulated CXCL1, CXCL5 and CXCL8 mRNA expression and secretion (Fig. $4 \mathrm{~A}, \mathrm{~B}, \mathrm{D}, \mathrm{E}, \mathrm{F}$ and G). The effect of butyrate and propionate pre-treatment was a significant attenuation of the mRNA expression and secretion of all CCL chemokines (Fig. 3),
CXCL1 (Fig. 4A and B), CXCL5 (Fig. 4D and E) and CXCL8 (Fig. $4 \mathrm{~F}$ and $\mathrm{G}$ ). There was, however, no effect of LPS or TNF, or butyrate and propionate, on CXCL2 or CXCL10 mRNA expression (Fig. 4C and $\mathrm{H}$ ).

In VAT, LPS and TNF significantly increased the mRNA expression and secretion of all CCL (Fig. 5) and CXCL chemokines (Fig. 6). Butyrate and propionate significantly suppressed LPS- and TNF-induced CCL2 mRNA expression and secretion (Fig. 5A and B) and LPSinduced CCL4 secretion (Fig. 5E). Furthermore, butyrate significantly suppressed LPS- and TNF-induced CCL4 (Fig. 5D) and CCL8 (Fig. 5F) mRNA expression. There was no effect of butyrate or propionate on LPS- or TNFinduced CCL3 mRNA expression (Fig. 5C). Butyrate and propionate significantly attenuated LPS-induced CXCL1, CXCL5, CXCL8 and CXCL10 mRNA expression and release of CXCL5 (Fig. 6A, D, E, F, H). Both treatments also significantly decreased TNF-induced CXCL5 and CXCL10 mRNA expression (Fig. 6D and H). Additionally, butyrate significantly decreased LPS-induced CXCL2 mRNA expression (Fig. 6C) and TNF-induced release of CXCL5 (Fig. 6E). There was no effect of either treatment on LPS- and TNF-induced CXCL1 and CXCL8 release (Fig. 6B and G) or on TNF-induced CXCL2 and CXCL8 mRNA expression (Fig. 6C and F).

In SAT, LPS and TNF significantly increased the mRNA expression and secretion of all CCL (Fig. 7) and CXCL chemokines (Fig. 8). Butyrate and propionate significantly decreased LPS- and TNF-induced CCL2 and 


\section{Visceral Adipose Tissue}

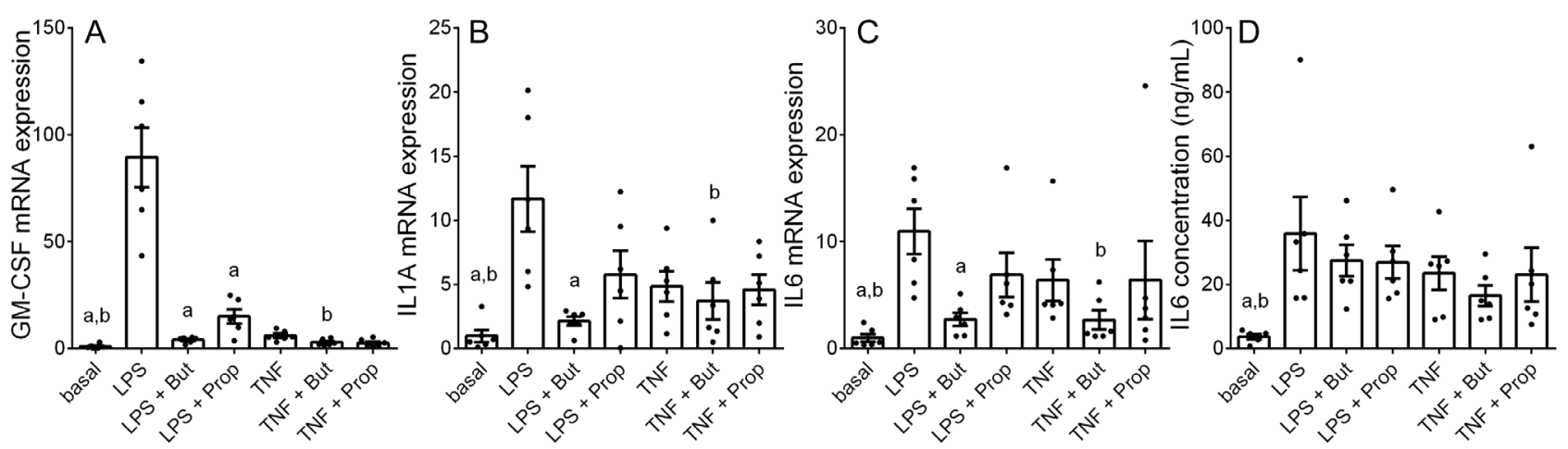

\section{Subcutaneous Adipose Tissue}
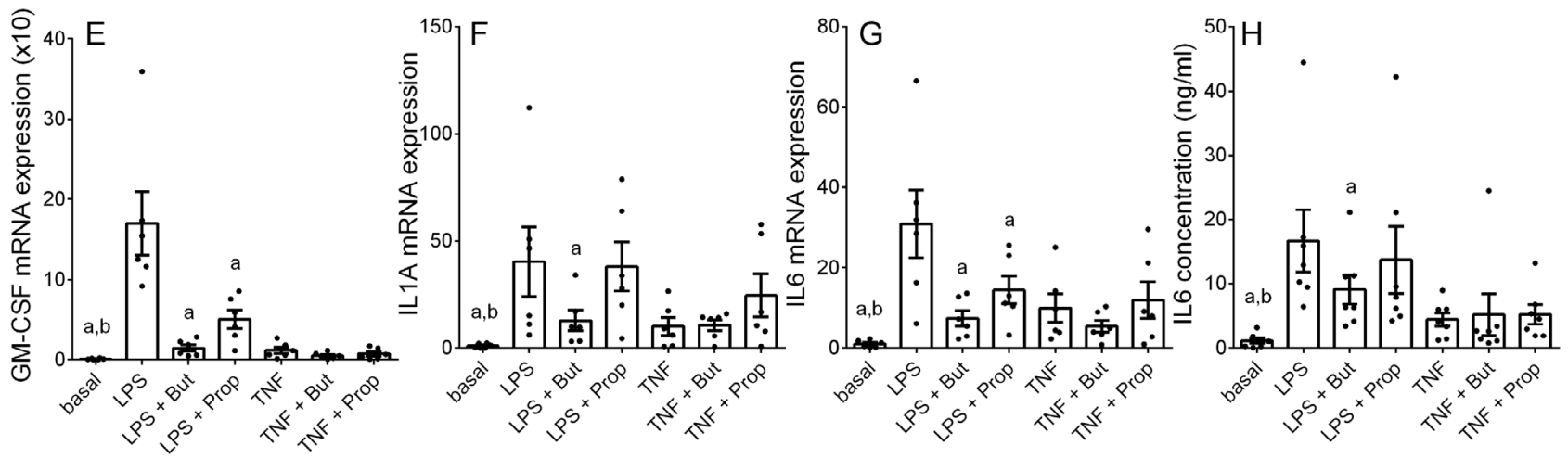

Figure 2

Effect of SCFAs on pro-inflammatory cytokines in VAT and SAT. Human (A, B, C and D) VAT ( $n=6$ patients) and (E, F, G and H) SAT ( $n=6-7$ patients) were incubated in the absence or presence of $5 \mathrm{mM}$ butyrate (But) or $10 \mathrm{mM}$ propionate (Prop) for $1 \mathrm{~h}$ and then treated with $10 \mu \mathrm{g} / \mathrm{mL} \mathrm{LPS}$ or $10 \mathrm{ng} / \mathrm{mL}$ TNF for a further 20 h. (A, B and C, E, F and G) GM-CSF, IL1A and IL6 mRNA expression was analysed by RT-qPCR and fold change was calculated relative to basal. ( $D$ and $H$ ) The concentration of IL6 in the incubation medium was assayed by ELISA. For all graphs, individual data points represent 6-7 independent experiments and displayed as mean \pm S.E.M. ${ }^{a} P \leq 0.05$ vs LPS, $P P \leq 0.05$ VS TNF; repeated measures one-way ANOVA.

CCL8 mRNA expression (Fig. 7A and F) and release of CCL2 (Fig. 7B). Butyrate and propionate significantly attenuated LPS-induced CCL4 mRNA expression (Fig. 7D). Butyrate also significantly decreased TNF-induced CCL4 mRNA expression and release (Fig. 7D and E). There was no effect of butyrate or propionate on CCL3 mRNA expression (Fig. 7C) or on LPS-induced CCL4 mRNA expression (Fig. 7E). Butyrate and propionate significantly attenuated LPS- and TNF-induced CXCL5 and CXCL10 mRNA expression (Fig. 8D and $\mathrm{H}$ ) and LPS-induced CXCL1 mRNA expression (Fig. 8A). Butyrate significantly decreased LPS- and TNF-induced release of CXCL5 (Fig. 8E) and TNF-induced release of CXCL1 (Fig. 8B). There was no effect of butyrate or propionate in SAT on CXCL2 and CXCL8 mRNA expression (Fig. 8C and F) and release of CXCL8 (Fig. 8G).

\section{Effect of butyrate and propionate on glucose uptake in skeletal muscle cells}

GDM is characterised by maternal hyperglycaemia due to defective insulin signalling leading to less glucose uptake in skeletal muscle (Lappas et al. 2005, Lappas 2014b, Bellamy et al. 2009). Studies have previously shown that TNF can cause similar defects in skeletal muscle (Lappas et al. 2005). Thus, the next aim was to determine if the SCFAs butyrate and propionate could restore the decrease in SMC glucose uptake by TNF. For these studies, primary SMCs were isolated from skeletal muscle obtained from NGT women at time of Caesarean section, differentiated and then incubated in the presence of TNF with or without butyrate or propionate. The cells were then stimulated with insulin and glucose uptake was measured 


\section{Placenta}
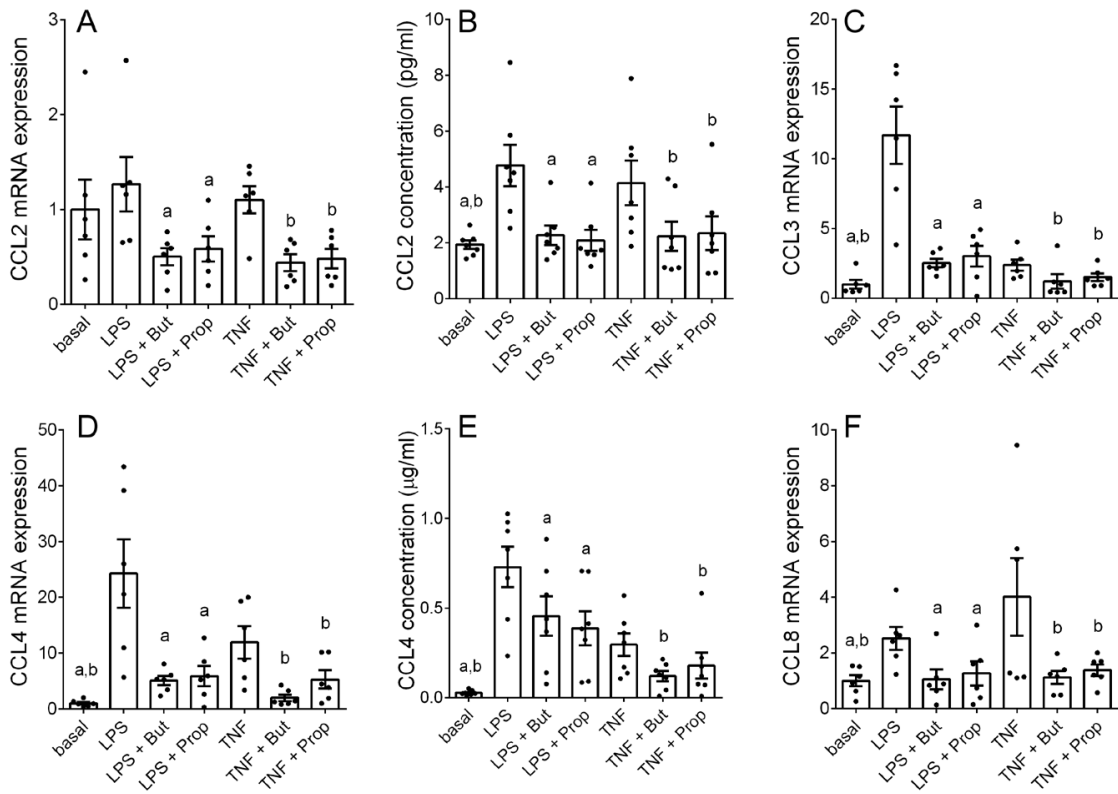

\section{Figure 3}

Effect of SCFAs on CCL chemokines in placenta. Human placenta was incubated in the absence or presence of $5 \mathrm{mM}$ butyrate (But) or $10 \mathrm{mM}$ propionate (Prop) for $1 \mathrm{~h}$ and then treated with $10 \mu \mathrm{g} / \mathrm{mL}$ LPS or $10 \mathrm{ng} / \mathrm{mL}$ TNF for a further $20 \mathrm{~h}$ ( $n=7$ patients). (A, C, D and F) CCL2, CCL3, CCL4 and CCL8 mRNA expression was analysed by RT-qPCR and fold change was calculated relative to basal. ( $B$ and $E$ ) The concentration of CCL2 and CCL4 in the incubation medium was assayed by ELISA. For all graphs, individual data points represent seven independent experiments and displayed as mean \pm S.E.M. ${ }^{a} P \leq 0.05$ vs LPS, ${ }^{b} P \leq 0.05$ Vs TNF; repeated measures one-way ANOVA.
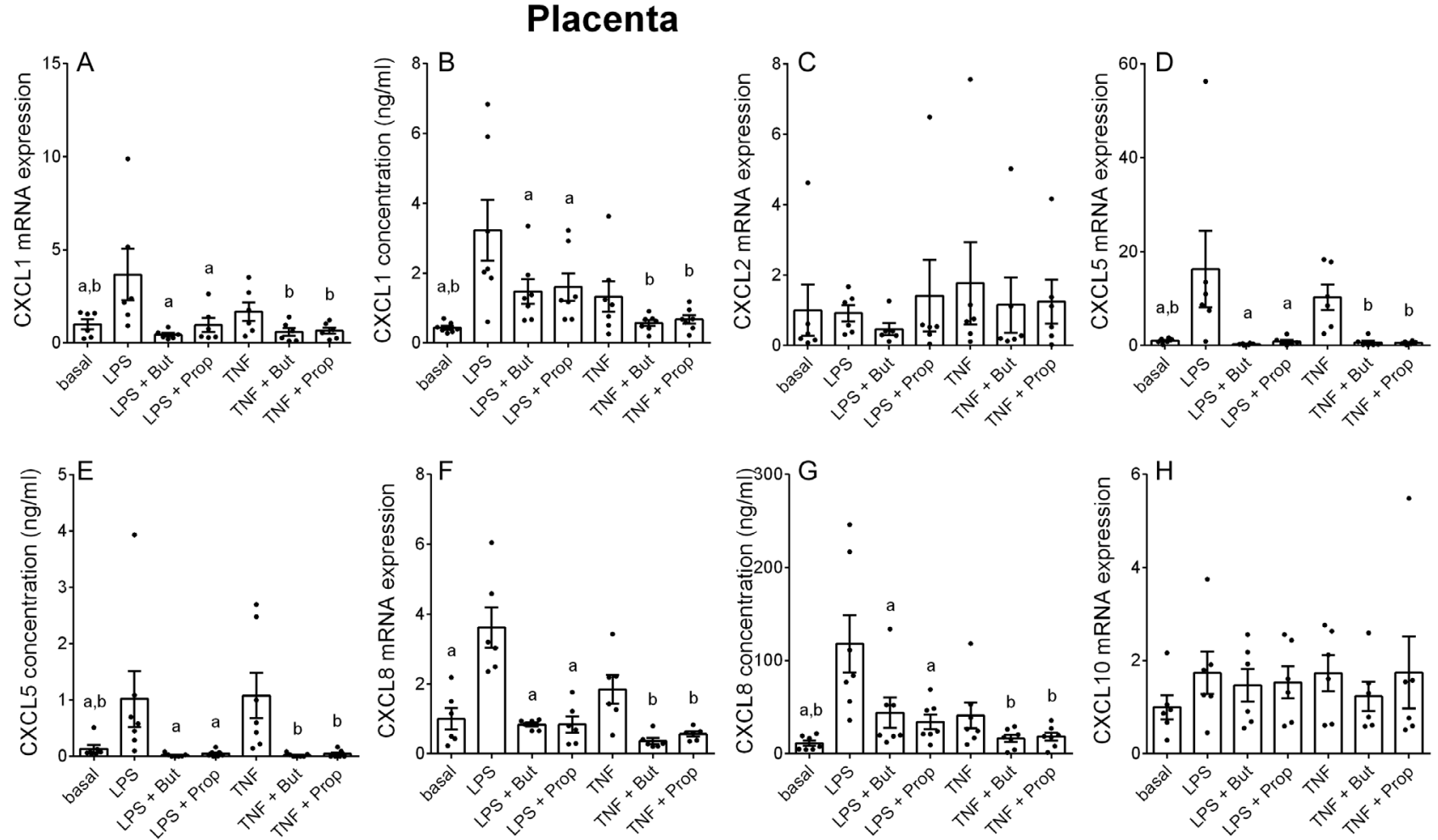

Figure 4

Effect of SCFAs on CXCL chemokines in placenta. Human placenta was incubated in the absence or presence of $5 \mathrm{mM}$ butyrate (But) or $10 \mathrm{mM}$ propionate (Prop) for $1 \mathrm{~h}$ and then treated with $10 \mu \mathrm{g} / \mathrm{mL}$ LPS or $10 \mathrm{ng} / \mathrm{mL}$ TNF for a further $20 \mathrm{~h}$ ( $n=7$ patients). (A, C, D, F and H) CXCL1, CXCL2, CXCL5, CXCL8 and CXCL10 mRNA expression was analysed by RT-qPCR and fold change was calculated relative to basal. (B, E and G) The concentration of CXCL1, CXCL5 and CXCL8 in the incubation medium was assayed by ELISA. For all graphs, individual data points represent seven independent experiments and displayed as mean \pm S.E.M. ${ }^{a} P \leq 0.05$ vs LPS, ${ }^{b} P \leq 0.05$ VS TNF; repeated measures one-way ANOVA. 


\section{Visceral Adipose Tissue}
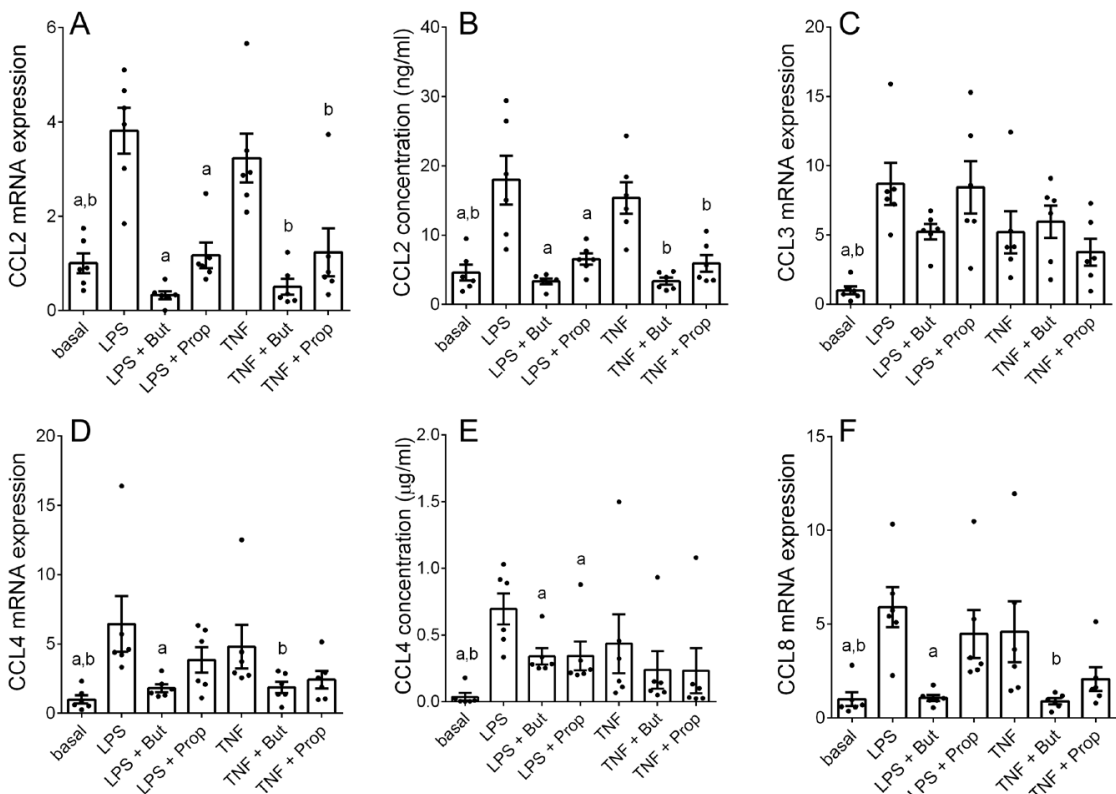

\section{Figure 5}

Effect of SCFAs on CCL chemokines in VAT. Human VAT was incubated in the absence or presence of $5 \mathrm{mM}$ butyrate (But) or $10 \mathrm{mM}$ propionate (Prop) for $1 \mathrm{~h}$ and then treated with $10 \mu \mathrm{g} / \mathrm{mL}$ LPS or $10 \mathrm{ng} / \mathrm{mL}$ TNF for a further $20 \mathrm{~h}$ ( $n=6$ patients). (A, C, D and F) CCL2, CCL3, CCL4 and CCL8 mRNA expression was analysed by RT-qPCR and fold change was calculated relative to basal. (B and $E$ ) The concentration of CCL2 and CCL4 in the incubation medium was assayed by ELISA. For all graphs, individual data points represent six independent experiments and displayed as mean \pm S.E.M. a $P \leq 0.05$ VS LPS, $b P \leq 0.05$ VS TNF; repeated measures one-way ANOVA.

\section{Visceral Adipose Tlssue}
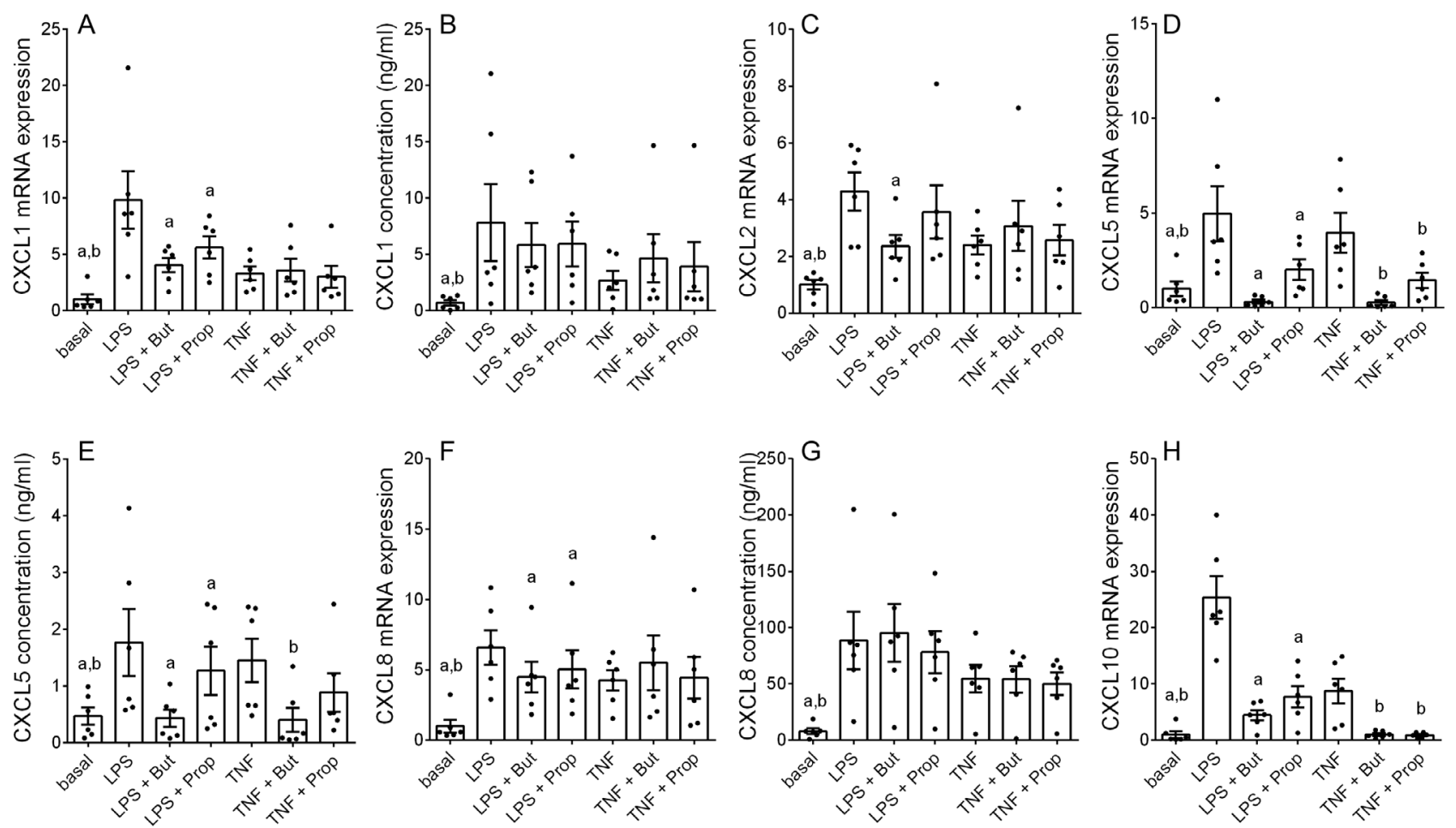

Figure 6

Effect of SCFAs on CXCL chemokines in VAT. Human VAT was incubated in the absence or presence of $5 \mathrm{mM}$ butyrate (But) or $10 \mathrm{mM}$ propionate (Prop) for $1 \mathrm{~h}$ and then treated with $10 \mu \mathrm{g} / \mathrm{mL}$ LPS or $10 \mathrm{ng} / \mathrm{mL}$ TNF for a further $20 \mathrm{~h}$ ( $n=6$ patients). (A, C, D, F and H) CXCL1, CXCL2, CXCL5, CXCL8 and CXCL10 mRNA expression was analysed by RT-qPCR and fold change was calculated relative to basal. (B, E and G) The concentration of CXCL1, CXCL5 and CXCL8 in the incubation medium was assayed by ELISA. For all graphs, individual data points represent six independent experiments and displayed as mean \pm S.E.M. ${ }^{P} P \leq 0.05$ VS LPS, $\mathrm{b} P \leq 0.05$ VS TNF; repeated measures one-way ANOVA. 


\section{Subcutaneous Adipose Tissue}
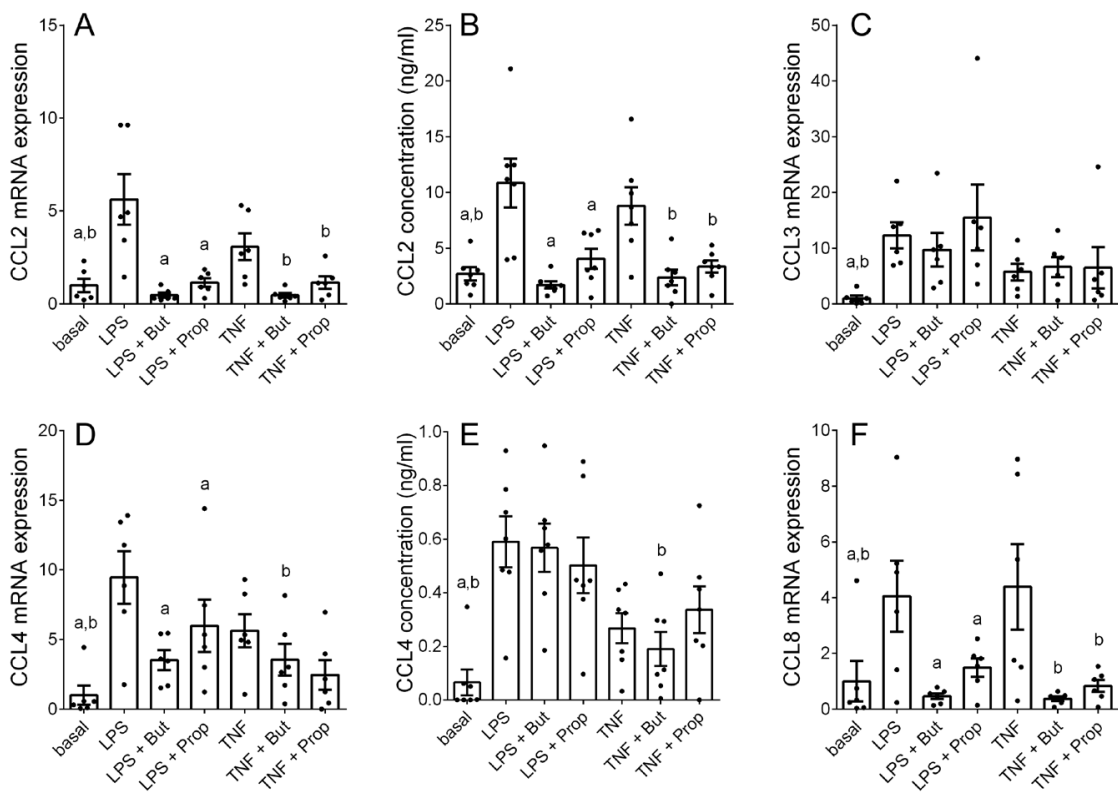

\section{Figure 7}

Effect of SCFAs on CCL chemokines in SAT. Human SAT was incubated in the absence or presence of $5 \mathrm{mM}$ butyrate (But) or $10 \mathrm{mM}$ propionate (Prop) for $1 \mathrm{~h}$ and then treated with $10 \mu \mathrm{g} / \mathrm{mL}$ LPS or $10 \mathrm{ng} / \mathrm{mL}$ TNF for a further $20 \mathrm{~h}$ ( $n=6-7$ patients). (A, C, D and F) CCL2, CCL3, CCL4 and CCL8 mRNA expression was analysed by RT-qPCR and fold change was calculated relative to basal. ( $\mathrm{B}$ and $\mathrm{E}$ ) The concentration of CCL2 and CCL4 in the incubation medium was assayed by ELISA. For all graphs, individual data points represent 6-7 independent experiments and displayed as mean \pm S.E.M. ${ }^{a} P \leq 0.05$ Vs LPS, ${ }^{b} P \leq 0.05$ vS TNF; repeated measures one-way ANOVA.

\section{Subcutaneous Adipose Tissue}
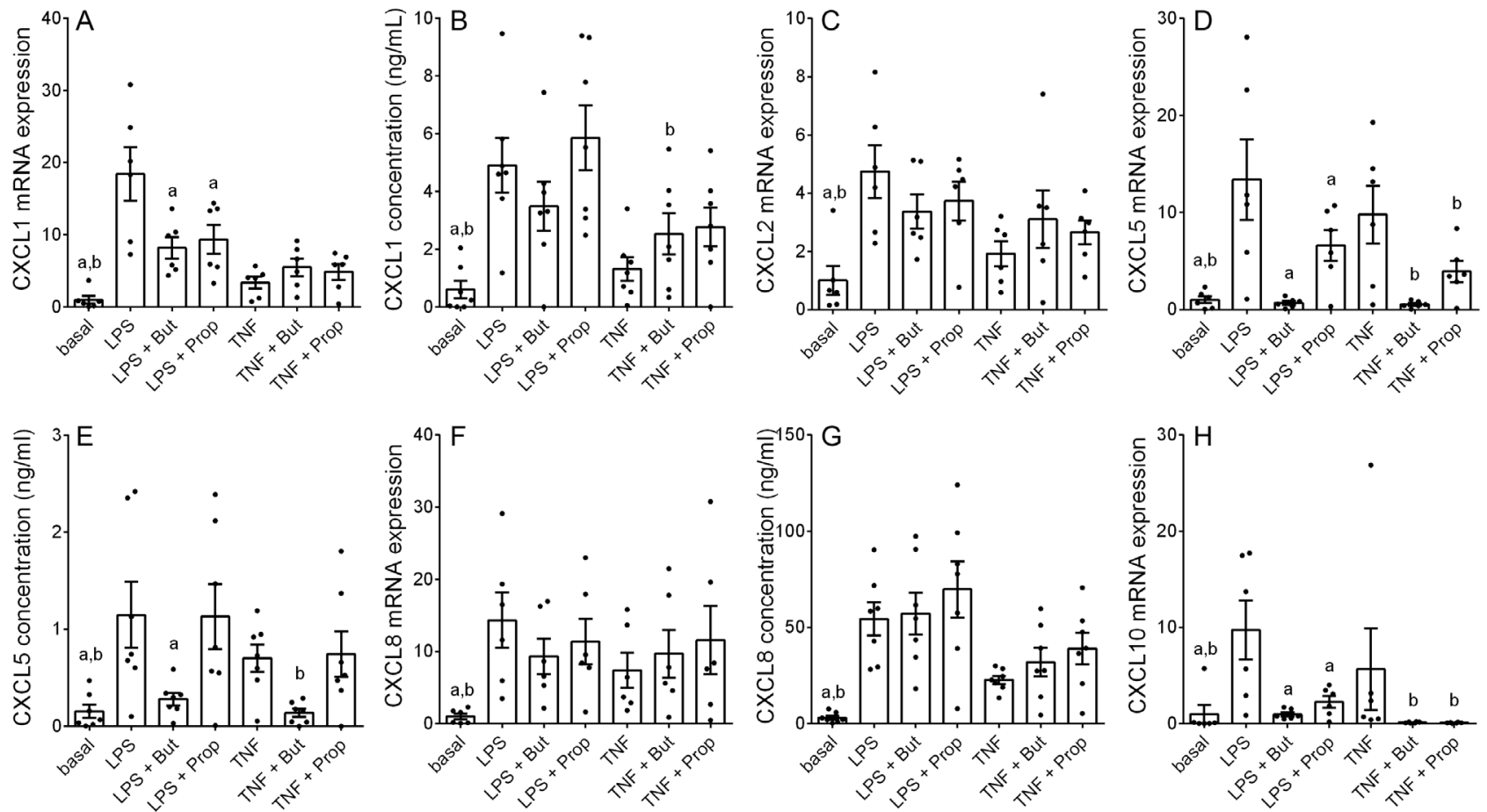

Figure 8

Effect of SCFAs on CXCL chemokines in SAT. Human SAT was incubated in the absence or presence of $5 \mathrm{mM}$ butyrate (But) or $10 \mathrm{mM}$ propionate (Prop) for $1 \mathrm{~h}$ and then treated with $10 \mu \mathrm{g} / \mathrm{mL}$ LPS or $10 \mathrm{ng} / \mathrm{mL}$ TNF for a further $20 \mathrm{~h}$ ( $n=6-7$ patients). (A, C, D, F and H) CXCL1, CXCL2, CXCL5, CXCL8 and CXCL10 mRNA expression was analysed by RT-qPCR and fold change was calculated relative to basal. (B, E and G) The concentration of CXCL1, CXCL5 and CXCL8 in the incubation medium was assayed by ELISA. For all graphs, individual data points represent 6-7 independent experiments and displayed as mean \pm S.E.M. aP $\leq 0.05$ vs LPS, ${ }^{b} P \leq 0.05$ vS TNF; repeated measures one-way ANOVA. 


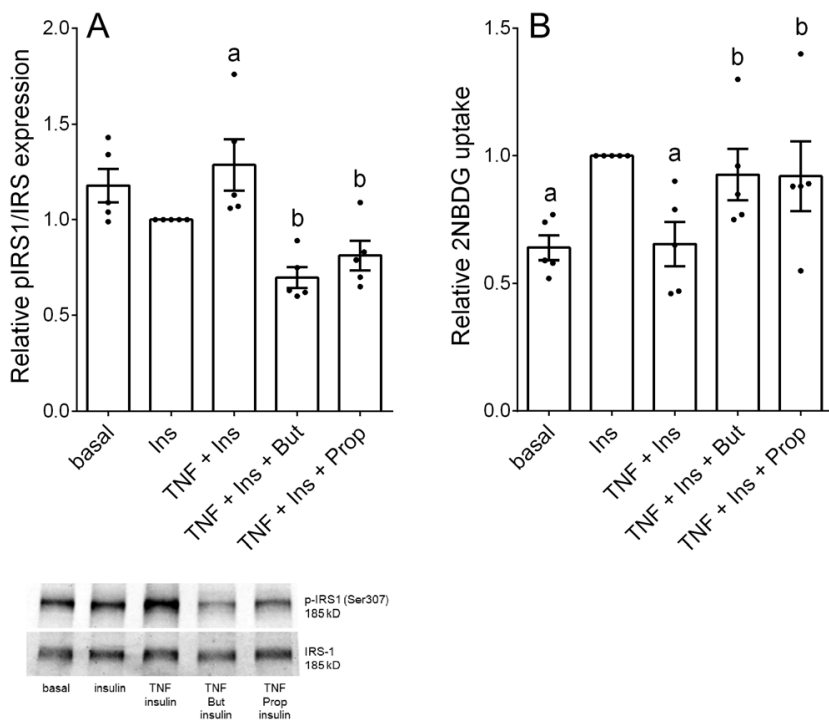

Figure 9

Effect of SCFAs on glucose uptake in skeletal muscle cells. Human SMCs ( $n=5$ patients) were incubated in the presence of $10 \mathrm{ng} / \mathrm{mL}$ TNF with or without $5 \mathrm{mM}$ butyrate (But) and $10 \mathrm{mM}$ propionate (Prop) for $20 \mathrm{~h}$, followed by 30 min incubation with $10 \mathrm{nM}$ insulin (Ins). (A) Phosphorylated serine IRS1 (pIRS1) protein expression was normalised to total IRS1. A representative Western blot from one patient is also shown. (B) Glucose uptake was measured by 2NBDG fluorescent assay. For all graphs, the data were calculated relative to the Ins group and displayed as mean \pm S.E.M. with data points representing five individual experiments. a $P \leq 0.05$ vs Ins, bP $\leq 0.05$ vs TNF+Ins; repeated measures one-way ANOVA.

using the fluorescent glucose analogue 2NBDG. The data are presented in Fig. 9. As expected, insulin significantly increased glucose uptake by $\sim 50 \%$. This increase in insulinstimulated glucose uptake was significantly attenuated by pre-incubation with TNF. The effect of co-treatment with butyrate was a significant restoration of glucose uptake by $\sim 40 \%$, back to levels like insulin-stimulated glucose uptake. On the other hand, propionate had no effect on the glucose uptake in the presence of TNF.

\section{Mechanisms by which butyrate and propionate exert their anti-inflammatory actions}

\section{Butyrate and propionate do not exert their effects via SCFA receptors}

It has been suggested that SCFAs may regulate inflammation by activating their FFAR2 and FFAR3 (Kobayashi et al. 2017, Li et al. 2018a,b). We then examined the effects of butyrate and propionate in regulating pro-inflammatory mediators in FFAR2 and FFAR3 deficient placental trophoblast cells treated with LPS (Supplementary Fig. 1, see section on supplementary data given at the end of this article). We first confirmed that siFFAR2 and siFFAR3 were effective in knocking down the targeted SCFAs. There was a 75\% decrease in FFAR2 mRNA expression in myometrial cells transfected with siFFAR2 (Supplementary Fig. 1A) and 75\% decrease in FFAR3 mRNA expression in myometrial cells transfected with siFFAR3 (Supplementary Fig. 1B). There was no effect of siFFAR2 on FFAR3 mRNA expression and siFFAR3 on FFAR2 mRNA expression. Our results show that the effects of butyrate and propionate are independent of FFAR2 or FFAR3 (Supplementary Fig. 1C and D). That is, the secretion of IL6 and CCL2 was not different in siFFAR2 or siFFAR3 transfected cells compared to siCONT transfected cells that were treated with butyrate and propionate.

\section{Butyrate and propionate inhibit activation of the MAPK protein ERK}

Mechanistically, butyrate and propionate have been shown to reduce inflammation via inhibition of key signalling pathways, such as the MAPK protein ERK (Chang et al. 2019). Thus, it was of interest to investigate whether butyrate and propionate may exert their antiinflammatory actions by inhibiting the activation of ERK. In placenta, 20 min treatment with LPS or TNF had no effect on pERK protein expression (Fig. 10A). Similar results were obtained in cells treated with LPS for 5-15 min and 2 and $20 \mathrm{~h}$ (data not shown). On the other hand, in omental adipose tissue, 20 min treatment with LPS or TNF significantly increased pERK protein expression Fig. 10B). In both placenta (Fig. 10A) and omental adipose tissue (Fig. 10B), pre-treatment with butyrate significantly decreased pERK protein expression in the presence of both LPS and TNF. In addition, propionate significantly decreased pERK protein expression in the presence of TNF; there was, however, no effect of propionate on activation of ERK in the presence LPS.

\section{Discussion}

To our knowledge, this is the first study that has explored the effects of the SCFAs acetate, butyrate and propionate on key pathways involved in the pathogenesis of GDM. To create a GDM-like state, LPS and TNF were used to treat placenta, visceral and s.c. adipose tissue and skeletal muscle cells in the absence or presence of SCFAs. For the first time, we have shown that the SCFAs propionate and butyrate significantly decrease inflammation-induced expression of pro-inflammatory mediators in human placenta and adipose tissue obtained from pregnant women. Propionate and butyrate were also able to 

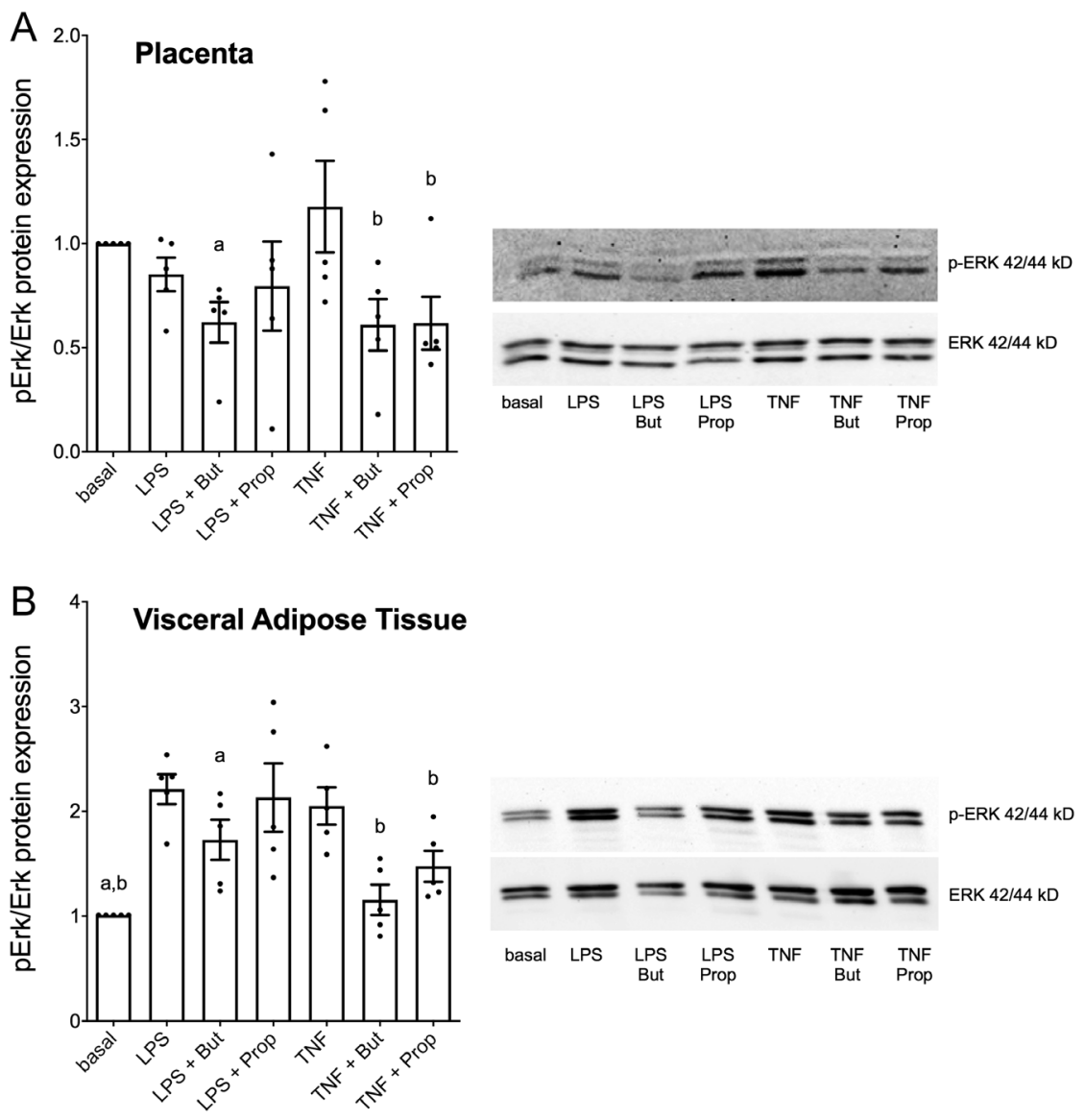

\section{Figure 10}

Effect of SCFAs on ERK activation. Human (A) placenta ( $n=5$ patients) and (B) VAT $(n=5$ patients) were incubated in the absence or presence of $5 \mathrm{mM}$ butyrate (But) or $10 \mathrm{mM}$ propionate (Prop) for $1 \mathrm{~h}$ and then treated with 10 $\mu \mathrm{g} / \mathrm{mL}$ LPS or $10 \mathrm{ng} / \mathrm{mL}$ TNF for a further $20 \mathrm{~min}$. The protein expression of phosphorylated ERK1 (pERK) and total ERK1 was analysed by Western blotting; pERK protein expression was normalised to total ERK expression. A representative Western blot from one patient is shown also shown. For all graphs, the data were calculated relative to basal and displayed as mean \pm S.E.M. with data points representing five individual experiments. ${ }^{a} P \leq$ 0.05 vs LPS, $\mathrm{b} P \leq 0.05$ vs TNF; repeated measures one-way ANOVA. significantly restore the impaired insulin signalling pathway and insulin-mediated glucose uptake in human skeletal muscle obtained from pregnant women induced by inflammation.

Low-grade maternal inflammation is a key feature of pregnancies complicated by GDM and thought to drive many of the characteristic features that define GDM (Pantham et al. 2015, Nguyen-Ngo et al. 2019). Sterile or infectious insults can induce low-grade systemic inflammation. Placenta and adipose tissue can respond to sterile and infectious inflammation by increasing expression of various cytokines and chemokines. Chemokines play an important role in the inflammatory response. The two main subfamilies of chemokines, CCL and CXCL, activate maternal peripheral leukocytes (a rich source of cytokines) and induce their infiltration into tissues. These leukocytes are a rich source of cytokines which can alter key pathways involved in the pathophysiology of GDM. They do this by inducing defects in the insulin signalling pathway in adipose tissue and skeletal muscle (Lappas 2014a), causing endothelial cell dysfunction (Lappas 2014c), altering placental nutrient transport (Jones et al. 2009, Lager et al. 2011), and increasing oxidative and endoplasmic reticulum stress (Lappas et al. 2011, Liong \& Lappas 2015).

In this study, placenta and adipose tissue (visceral and s.c.) from normal pregnant women were stimulated with the pro-inflammatory cytokine TNF and the bacterial product LPS to induce an inflammatory state as evidenced by increased expression and production of pro-inflammatory cytokines and chemokines. Butyrate and propionate pre-treatment could significantly suppress LPS- and TNF-induced inflammatory cytokine and chemokine mRNA expression and protein secretion in placenta, VAT and SAT. Collectively, this suggests that the SCFAs butyrate and propionate can attenuate the progression of pro-inflammatory cytokine and chemokine accumulation and limit the recruitment of immune cells to placenta and adipose tissue to prevent the propagation of the inflammatory response.

Peripheral insulin resistance increases as pregnancy progresses in order to provide adequate nutrient transfer to the growing neonate (Catalano et al. 1993). In GDM, however, there is exaggerated insulin resistance which contributes to short- and long-term metabolic abnormalities in the offspring (Friedman 2015). 
GDM pregnancies display reduced pancreatic $\beta$-cell function by $30-70 \%$, indicating $\beta$-cells are unable to compensate for the insulin resistant state of normal pregnancy (Xiang et al. 1999). This is then further exacerbated by defective insulin signalling in adipose tissue and skeletal muscle (Colomiere et al. 2010, Catalano 2014). GDM patients exhibit reduced IRS-1 and increased serine IRS-1 phosphorylation in skeletal muscle (Shao et al. 2002, Barbour et al. 2007, Colomiere et al. 2010) thereby inhibiting glucose uptake. We have previously shown that TNF can decrease skeletal muscle glucose uptake by interfering with proteins involved in the insulin signalling pathway (Tran et al. 2017). Thus, it was of interest to determine if the SCFAs butyrate and propionate could restore the defects in the insulin signalling pathways and glucose uptake induced by TNF. In our study, butyrate and propionate pre-treatment reversed TNF-induced increase of IRS-1 serine phosphorylation and decrease in insulinstimulated glucose uptake in skeletal muscle cells. In support of our findings, butyrate and propionate increase glucose uptake by promoting GLUT4 gene expression in C2C12 myotubes and adipocytes in vitro (Han et al. 2014, Heimann et al. 2015). Several animal studies have also shown that SCFAs can improve insulin sensitivity (Canfora et al. 2015, Weitkunat et al. 2017). It should be noted that, while skeletal muscle contributes to $75 \%$ of glucose uptake that occurs in the body (Stump et al. 2006), adipose tissue, and in particular VAT, it also play a role in insulin signalling and diabetes development. Due to technical difficulties, we could did not assess glucose uptake and insulin signalling in primary adipocytes isolated from VAT from pregnant women.

SCFAs can elicit their actions by binding to and activating the SCFA receptors FFAR2 and FFAR3 (Li et al. $2018 b$ ). For example, inhibition of CCL2 expression by SCFAs was suppressed by FFAR2 and FFAR3 siRNA in human renal cortical epithelial cells (Kobayashi et al. 2017) and FFAR2 and FFAR3 activators attenuated the inhibitory effects of SCFAs on IL6 secretion in endothelial cells (Li et al. 2018a). Other studies have, however, reported that SCFAs act independently of FFAR2 and FFAR3 to suppress inflammation (Andrade-Oliveira et al. 2015, Li et al. 2018a), protect against diet-induced obesity and regulate gut hormones (Lin et al. 2012) and induce neutrophil apoptosis (Aoyama et al. 2010). These studies have shown that butyrate and propionate exert their effects by inhibiting histone deactylases (HDAC). In this study, the inhibitory effects of butyrate and propionate on inflammation are independent of FFAR2 or FFAR3. We found that inhibition of pro-inflammatory cytokine IL6 and the chemokine CCL2 was not suppressed in placental cells deficient in FFAR2 and FFAR3. The ability of butyrate and propionate to act as HDAC inhibitors is an avenue of future research.

Downstream of activating FFAR2 and FFAR3 or inhibiting HDACs, SCFAs exert their anti-inflammatory actions by interfering with the activation of key signalling proteins including the MAPK protein ERK (Chang et al. 2019). Likewise, our results indicate that butyrate and propionate inhibit the activation ERK in placenta and VAT and that these are specific. That is, butyrate and propionate significantly decreased activation of ERK in the presence of TNF in both placenta and VAT. On the other hand, butyrate, but not propionate, significantly decreased activation of ERK in the presence of LPS in both placenta and VAT. Taken together, our results suggest that the antiinflammatory and anti-diabetic effects of butyrate and propionate are mediated by inhibition of ERK activation.

In this study, we found that the SCFAs butyrate and propionate improved maternal skeletal muscle glucose uptake and prevented inflammation in placenta and maternal adipose tissue in an in vitro model of GDM. These findings are of relevance given that maternal and placental inflammation (Pantham et al. 2015, NguyenNgo et al. 2019) and maternal peripheral insulin resistance (Colomiere et al. 2010, Catalano 2014, Friedman 2015) are two key features of GDM. Importantly, these studies support the evidence that dietary therapies have protective effects against inflammation and insulin resistance and reduce the risk of developing GDM (Agha-Jaffar et al. 2016, Assaf-Balut et al. 2017) and that a low fibre diet is associated with an increased risk of developing GDM (Zhang et al. 2006). What is not known, however, is if SCFAs can prevent the development of GDM and improve neonatal outcomes. Therefore, further in vivo studies are warranted to determine the effectiveness and safety of butyrate and propionate as novel therapeutic agents for preventing GDM.

\section{Supplementary materials}

This is linked to the online version of the paper at https://doi.org/10.1530/ JME-20-0094.

\section{Declaration of interest}

The authors declare that there is no conflict of interest that could be perceived as prejudicing the impartiality of the research reported.

\section{Funding}

Associate Professor Martha Lappas is supported by a Research Fellowship from the Department of Obstetrics and Gynaecology (University of Melbourne) and a Faculty Fellowship from the University of Melbourne. 
Caitlyn Nguyen-Ngo is supported by an Australian Government Research Training Program (RTP) Scholarship. Funding for this study was provided by the Norman Beischer Medical Research Foundation and Austin Medical Research Foundation (AMRF).

\section{Author contribution statement}

$M L$ conceived and designed the study, analysed the data and wrote the initial draft of the manuscript. R R and C N N performed the experiments and edited the manuscript.

\section{Acknowledgements}

The following are gratefully acknowledged by the authors: Dr Ratana Lim (University of Melbourne) for her excellent technical assistance; the clinical Research Midwives Gabrielle Pell, Genevieve Christophers, and Rachel Murdoch for sample collection; the Obstetrics and Midwifery staff of the Mercy Hospital for Women for their co-operation; and the women who generously donated their tissue samples to the study.

\section{References}

Agha-Jaffar R, Oliver N, Johnston D \& Robinson S 2016 Gestational diabetes mellitus: does an effective prevention strategy exist? Nature Reviews: Endocrinology 12 533-546. (https://doi.org/10.1038/ nrendo.2016.88)

Andrade-Oliveira V, Amano MT, Correa-Costa M, Castoldi A, Felizardo RJF, de Almeida DC, Bassi EJ, Moraes-Vieira PM, Hiyane MI, Rodas AC, et al. 2015 Gut bacteria products prevent AKI induced by ischemia-reperfusion. Journal of the American Society of Nephrology 26 1877-1888. (https://doi.org/10.1681/ASN.2014030288)

Aoyama M, Kotani J \& Usami M 2010 Butyrate and propionate induced activated or non-activated neutrophil apoptosis via HDAC inhibitor activity but without activating GPR-41/GPR-43 pathways. Nutrition 26 653-661. (https://doi.org/10.1016/j.nut.2009.07.006)

Assaf-Balut C, Garcia de la Torre N, Duran A, Fuentes M, Bordiu E, Del Valle L, Familiar C, Ortola A, Jimenez I, Herraiz MA, et al. 2017 A mediterranean diet with additional extra virgin olive oil and pistachios reduces the incidence of gestational diabetes mellitus (GDM): a randomized controlled trial: the St. Carlos GDM prevention study. PLoS One 12 e0185873. (https://doi.org/10.1371/ journal.pone.0185873)

Barbour LA, McCurdy CE, Hernandez TL Kirwan JP, Catalano PM \& Friedman JE 2007 Cellular mechanisms for insulin resistance in normal pregnancy and gestational diabetes. Diabetes Care 30 S112-S119. (https://doi.org/10.2337/dc07-s202)

Bellamy L, Casas JP, Hingorani AD \& Williams D 2009 Type 2 diabetes mellitus after gestational diabetes: a systematic review and metaanalysis. Lancet 373 1773-1779. (https://doi.org/10.1016/S01406736(09)60731-5)

Bergman EN 1990 Energy contributions of volatile fatty-acids from the gastrointestinal-tract in various species. Physiological Reviews 70 567-590. (https://doi.org/10.1152/physrev.1990.70.2.567)

Brawerman GM \& Dolinsky VW 2018 Therapies for gestational diabetes and their implications for maternal and offspring health: evidence from human and animal studies. Pharmacological Research 130 52-73. (https://doi.org/10.1016/j.phrs.2018.02.002)

Canfora EE, Jocken JW \& Blaak EE 2015 Short-chain fatty acids in control of body weight and insulin sensitivity. Nature Reviews: Endocrinology 11 577-591. (https://doi.org/10.1038/nrendo.2015.128)

Catalano PM 2014 Trying to understand gestational diabetes. Diabetic Medicine 31 273-281. (https://doi.org/10.1111/dme.12381)

Catalano PM, Tyzbir ED, Wolfe RR, Calles J, Roman NM, Amini SB \& Sims EA 1993 Carbohydrate metabolism during pregnancy in control subjects and women with gestational diabetes. American Journal of
Physiology 264 E60-E67. (https://doi.org/10.1152/ ajpendo.1993.264.1.E60)

Chang G, Ma N, Zhang H, Wang Y, Huang J, Liu J, Dai H \& Shen X 2019 Sodium butyrate modulates mucosal inflammation injury mediated by GPR41/43 in the cecum of goats fed a high concentration diet. Frontiers in Physiology 10 1130. (https://doi. org/10.3389/fphys.2019.01130)

Colomiere M, Permezel M \& Lappas M 2010 Diabetes and obesity during pregnancy alter insulin signalling and glucose transporter expression in maternal skeletal muscle and subcutaneous adipose tissue. Journal of Molecular Endocrinology 44 213-223. (https://doi. org/10.1677/JME-09-0091)

Damm P, Houshmand-Oeregaard A, Kelstrup L, Lauenborg J, Mathiesen ER \& Clausen TD 2016 Gestational diabetes mellitus and long-term consequences for mother and offspring: a view from Denmark. Diabetologia 59 1396-1399. (https://doi.org/10.1007/s00125-016-3985-5)

Friedman JE 2015 Obesity and gestational diabetes mellitus pathways for programming in mouse, monkey, and man-where do we go next? The 2014 Norbert Freinkel award lecture. Diabetes Care $\mathbf{3 8}$ 1402-1411. (https://doi.org/10.2337/dc15-0628)

Gao Z, Yin J, Zhang J, Ward RE, Martin RJ, Lefevre M, Cefalu WT \& Ye J 2009 Butyrate improves insulin sensitivity and increases energy expenditure in mice. Diabetes 58 1509-1517. (https://doi. org/10.2337/db08-1637)

Gill PA, van Zelm MC, Muir JG \& Gibson PR 20182018 short chain fatty acids as potential therapeutic agents in human gastrointestinal and inflammatory disorders. Alimentary Pharmacology and Therapeutics 48 15-34. (https://doi.org/10.1111/apt.14689)

Han JH, Kim IS, Jung SH, Lee SG, Son HY \& Myung CS 2014 The effects of propionate and valerate on insulin responsiveness for glucose uptake in 3T3-L1 adipocytes and C2C12 myotubes via G proteincoupled receptor 41. PLoS One 9 e95268. (https://doi.org/10.1371/ journal.pone.0095268)

Hanley JA, Weeks A \& Wray S 2015 Physiological increases in lactate inhibit intracellular calcium transients, acidify myocytes and decrease force in term pregnant rat myometrium. Journal of Physiology 593 4603-4614. (https://doi.org/10.1113/JP270631)

Heimann E, Nyman M \& Degerman E 2015 Propionic acid and butyric acid inhibit lipolysis and de novo lipogenesis and increase insulinstimulated glucose uptake in primary rat adipocytes. Adipocyte $\mathbf{4}$ 81-88. (https://doi.org/10.4161/21623945.2014.960694)

Henagan TM, Stefanska B, Fang Z, Navard AM, Ye J, Lenard NR \& Devarshi PP 2015 Sodium butyrate epigenetically modulates high-fat diet-induced skeletal muscle mitochondrial adaptation, obesity and insulin resistance through nucleosome positioning. British Journal of Pharmacology 172 2782-2798. (https://doi.org/10.1111/bph.13058)

Jones HN, Jansson T \& Powell TL 2009 IL-6 stimulates system A amino acid transporter activity in trophoblast cells through STAT3 and increased expression of SNAT2. American Journal of Physiology: Cell Physiology 297 C1228-C1235. (https://doi.org/10.1152/ajpcell.00195.2009)

Kobayashi M, Mikami D, Kimura H, Kamiyama K, Morikawa Y, Yokoi S, Kasuno K, Takahashi N, Taniguchi T \& Iwano M 2017 Short-chain fatty acids, GPR41 and GPR43 ligands, inhibit TNF-alpha-induced MCP-1 expression by modulating p38 and JNK signaling pathways in human renal cortical epithelial cells. Biochemical and Biophysical Research Communications 486 499-505. (https://doi.org/10.1016/j. bbrc.2017.03.071)

Lager S, Jansson N, Olsson AL, Wennergren M, Jansson T \& Powell TL 2011 Effect of IL-6 and TNF-alpha on fatty acid uptake in cultured human primary trophoblast cells. Placenta 32 121-127. (https://doi. org/10.1016/j.placenta.2010.10.012)

Lappas M 2014a Activation of inflammasomes in adipose tissue of women with gestational diabetes. Molecular and Cellular Endocrinology 382 74-83. (https://doi.org/10.1016/j.mce.2013.09.011)

Lappas M 2014b GSK3beta is increased in adipose tissue and skeletal muscle from women with gestational diabetes where it regulates the (c) 2020 Society for Endocrinology Published by Bioscientifica Ltd. Printed in Great Britain 
inflammatory response. PLoS One 9 e115854. (https://doi. org/10.1371/journal.pone.0115854)

Lappas M 2014c Markers of endothelial cell dysfunction are increased in human omental adipose tissue from women with pre-existing maternal obesity and gestational diabetes. Metabolism: Clinical and Experimental 63 860-873. (https://doi.org/10.1016/j.metabol.2014.03.007)

Lappas M, Permezel M, Georgiou HM \& Rice GE 2004 Regulation of phospholipase isozymes by nuclear factor-kappaB in human gestational tissues in vitro. Journal of Clinical Endocrinology and Metabolism 89 2365-2372. (https://doi.org/10.1210/jc.2003-031385)

Lappas M, Yee K, Permezel M \& Rice GE 2005 Release and regulation of leptin, resistin and adiponectin from human placenta, fetal membranes, and maternal adipose tissue and skeletal muscle from normal and gestational diabetes mellitus-complicated pregnancies. Journal of Endocrinology 186 457-465. (https://doi.org/10.1677/joe.1.06227)

Lappas M, Hiden U, Desoye G, Froehlich J, Hauguel-De Mouzon S \& Jawerbaum A 2011 The role of oxidative stress in the pathophysiology of gestational diabetes mellitus. Antioxidants and Redox Signaling 15 3061-3100. (https://doi.org/10.1089/ ars.2010.3765)

Li HP, Chen X \& Li MQ 2013 Butyrate alleviates metabolic impairments and protects pancreatic beta cell function in pregnant mice with obesity. International Journal of Clinical and Experimental Pathology 6 1574-1584.

Li M, van Esch BCAM, Henricks PAJ, Folkerts G \& Garssen J 2018a The anti-inflammatory effects of short chain fatty acids on lipopolysaccharide- or tumor necrosis factor alpha-stimulated endothelial cells via activation of GPR41/43 and inhibition of HDACs. Frontiers in Pharmacology 9 533. (https://doi.org/10.3389/ fphar.2018.00533)

Li M, van Esch BCAM, Wagenaar GTM, Garssen J, Folkerts G \& Henricks PAJ $2018 b$ Pro- and anti-inflammatory effects of short chain fatty acids on immune and endothelial cells. European Journal of Pharmacology 831 52-59. (https://doi.org/10.1016/j.ejphar.2018.05.003)

Liang HL, Ma SJ, Xiao YN \& Tan HZ 2017 Comparative efficacy and safety of oral antidiabetic drugs and insulin in treating gestational diabetes mellitus: an updated PRISMA-compliant network metaanalysis. Medicine 96 e7939. (https://doi.org/10.1097/ MD.0000000000007939)

Lim R, Barker G \& Lappas M 2013a SIRT6 is decreased with preterm labor and regulates key terminal effector pathways of human labor in fetal membranes. Biology of Reproduction 88 17. (https://doi. org/10.1095/biolreprod.112.105163)

Lim R, Barker G, Wall CA \& Lappas M 2013b Dietary phytophenols curcumin, naringenin and apigenin reduce infection-induced inflammatory and contractile pathways in human placenta, foetal membranes and myometrium. Molecular Human Reproduction 19 451-462. (https://doi.org/10.1093/molehr/gat015)

Lin HV, Frassetto A, Kowalik EJ Jr, Nawrocki AR, Lu MM, Kosinski JR, Hubert JA, Szeto D, Yao X, Forrest G, et al. 2012 Butyrate and propionate protect against diet-induced obesity and regulate gut hormones via free fatty acid receptor 3-independent mechanisms. PLoS One 7 e35240. (https://doi.org/10.1371/journal.pone.0035240)

Liong S \& Lappas M 2015 Endoplasmic reticulum stress is increased in adipose tissue of women with gestational diabetes. PLoS One $\mathbf{1 0}$ e0122633. (https://doi.org/10.1371/journal.pone.0122633)

McNabney SM \& Henagan TM 2017 Short chain fatty acids in the colon and peripheral tissues: a focus on butyrate, colon cancer, obesity and insulin resistance. Nutrients 9 1348. (https://doi.org/10.3390/ nu9121348)
Nguyen-Ngo C, Jayabalan N, Salomon C \& Lappas M 2019 Molecular pathways disrupted by gestational diabetes mellitus. Journal of Molecular Endocrinology 63 R51-R72. (https://doi.org/10.1530/JME-18-0274)

Pantham P, Aye IL \& Powell TL 2015 Inflammation in maternal obesity and gestational diabetes mellitus. Placenta 36 709-715. (https://doi. org/10.1016/j.placenta.2015.04.006)

Reece EA 2010 The fetal and maternal consequences of gestational diabetes mellitus. Journal of Maternal-Fetal and Neonatal Medicine $\mathbf{2 3}$ 199-203. (https://doi.org/10.3109/14767050903550659)

Sanna S, van Zuydam NR, Mahajan A, Kurilshikov A, Vich Vila A, Vosa U, Mujagic Z, Masclee AAM, Jonkers DMAE, Oosting M, et al. 2019 Causal relationships among the gut microbiome, short-chain fatty acids and metabolic diseases. Nature Genetics 51 600-605. (https://doi.org/10.1038/s41588-019-0350-x)

Segain J-P, de la Blétière DR, Bourreille A, Leray V, Gervois N, Rosales C, Ferrier L, Bonnet C, Blottière HM \& Galmiche J-P 2000 Butyrate inhibits inflammatory responses through NFkB inhibition: implications for Crohn's disease. Gut 47 397-403. (https://doi. org/10.1136/gut.47.3.397)

Shao J, Yamashita H, Qiao L, Draznin B \& Friedman JE 2002 Phosphatidylinositol 3-kinase redistribution is associated with skeletal muscle insulin resistance in gestational diabetes mellitus. Diabetes 51 19-29. (https://doi.org/10.2337/diabetes.51.1.19)

Stump CS, Henriksen EJ, Wei Y \& Sowers JR 2006 The metabolic syndrome: role of skeletal muscle metabolism. Annals of Medicine $\mathbf{3 8}$ 389-402. (https://doi.org/10.1080/07853890600888413)

Tan J, McKenzie C, Potamitis M, Thorburn AN, Mackay CR \& Macia L 2014 The role of short-chain fatty acids in health and disease. Advances in Immunology 121 91-119. (https://doi.org/10.1016/B9780-12-800100-4.00003-9)

Tran HT, Liong S, Lim R, Barker G \& Lappas M 2017 Resveratrol ameliorates the chemical and microbial induction of inflammation and insulin resistance in human placenta, adipose tissue and skeletal muscle. PLoS One 12 e0173373. (https://doi.org/10.1371/journal.pone.0173373)

Voltolini C, Battersby S, Etherington SL, Petraglia F, Norman JE \& Jabbour HN 2012 A novel antiinflammatory role for the short-chain fatty acids in human labor. Endocrinology 153 395-403. (https://doi. org/10.1210/en.2011-1457)

Weitkunat K, Schumann S, Nickel D, Hornemann S, Petzke KJ, Schulze MB, Pfeiffer AF \& Klaus S 2017 Odd-chain fatty acids as a biomarker for dietary fiber intake: a novel pathway for endogenous production from propionate. American Journal of Clinical Nutrition 105 1544-1551. (https://doi.org/10.3945/ajcn.117.152702)

Xiang AH, Peters RK, Trigo E, Kjos SL, Lee WP \& Buchanan TA 1999 Multiple metabolic defects during late pregnancy in women at high risk for type 2 diabetes. Diabetes $\mathbf{4 8} 848-854$. (https://doi. org/10.2337/diabetes.48.4.848)

Yuen L, Saeedi P, Riaz M, Karuranga S, Divakar H, Levitt N, Yang X \& Simmons D 2019 Projections of the prevalence of hyperglycaemia in pregnancy in 2019 and beyond: results from the International Diabetes Federation Diabetes Atlas, 9th ed. Diabetes Research and Clinical Practice 157 107841. (https://doi.org/10.1016/j.diabres.2019.107841)

Zhang C, Liu S, Solomon CG \& Hu FB 2006 Dietary fiber intake, dietary glycemic load, and the risk for gestational diabetes mellitus. Diabetes Care 29 2223-2230. (https://doi.org/10.2337/dc06-0266)

Zhu H, Chen B, Cheng Y, Zhou Y, Yan YS, Luo Q, Jiang Y, Sheng JZ, Ding GL \& Huang HF 2019 Insulin therapy for gestational diabetes mellitus does not fully protect offspring From diet-induced metabolic disorders. Diabetes 68 696-708. (https://doi.org/10.2337/ db18-1151)

Received in final form 26 May 2020

Accepted 1 June 2020

Accepted Manuscript published online 1 June 2020 (c) 2020 Society for Endocrinology Published by Bioscientifica Ltd. Printed in Great Britain 